\title{
Fenologia de espécies arbóreas zoocóricas em uma floresta psamófila no sul do Brasil
}

\author{
Maria Salete Marchioretto ${ }^{1,3}$, Julian Mauhs ${ }^{1}$ e Jean Carlos Budke ${ }^{2}$
}

Recebido em 30/11/2005. Aceito em 29/08/2006

\begin{abstract}
RESUMO - (Fenologia de espécies arbóreas zoocóricas em uma floresta psamófila no sul do Brasil). Os fenômenos biológicos estão sujeitos a fatores abióticos que variam de acordo com a posição geográfica, especialmente relacionados à sazonalidade do ambiente. O presente estudo avaliou por dois anos as fenofases vegetativas e reprodutivas de nove espécies em uma floresta psamófila no sul do Brasil. Foram avaliados os eventos de queda foliar, brotamento, floração e frutificação em indivíduos localizados em diferentes pontos da área de estudo. A queda de folhas foi maior no mês de julho, sendo correlacionada com a menor temperatura média mensal e o menor comprimento do dia. As espécies apresentaram um aumento nas taxas de brotação após a queda foliar, atingindo maior atividade de setembro a novembro. Floração e frutificação apresentaram ritmos variados, sendo que houve maior produção de flores durante outubro e produção de frutos maximizada em novembro. A ausência de estação seca definida sugere que as espécies não experimentam restrições hídricas em intervalos regulares. Por outro lado, os eventos fenológicos vegetativos e reprodutivos estão estreitamente relacionados às variações anuais de temperatura média e comprimento do dia.
\end{abstract}

Palavras-chave: Brotação, fotoperíodo, queda foliar, restinga, sazonalidade

\begin{abstract}
Phenology of zoochorous tree species in a sandy coastal forest in Southern Brazil). Biological phenomena are subject to abiotic factors that change according to geographical position, especially those related to environmental seasonality. This study provides a two-year assessment of vegetative and reproductive phenophases for nine species in a coastal forest on sandy soil in Southern Brazil. Changes in leaf fall, leaf flush, flowering and fruiting of trees from different locations within the fragment were evaluated. Leaf fall was higher in July and it was correlated with lower monthly average temperature and shorter day length. There was an increase of flushing rates after the highest leaf-fall activity from September to November. Flowering and fruiting had different rhythms; flower production was highest in October while fruit production was highest in November. The lack of a dry season suggests species do not experiment water-deficiency at regular intervals. On the other hand, vegetative and reproductive phenophases were related to variations in average temperature and day length throughout the year.
\end{abstract}

Key words: day length, leaf fall, leaf flush, restinga, seasonality

\section{Introdução}

A fenologia pode ser definida como o estudo da ocorrência de eventos vegetativos e reprodutivos das plantas no decorrer do ano, bem como das relações com fatores ambientais e bióticos (Lieth \& Schultz 1976). Entre os fatores ambientais, os climáticos apresentam geralmente relações próximas com os eventos fenológicos, permitindo estabelecer padrões preliminares para uma população, sinúsia ou comunidade e, revelando aspectos importantes sobre a dinâmica dos ecossistemas (Morellato \& Leitão Filho 1992; Marques et al. 2004).
No Brasil, os estudos fenológicos são relativamente recentes, sendo que as regiões sudeste e sul apresentam um bom número de trabalhos publicados, especialmente em florestas ombrófilas densas (Alvim \& Alvim 1976; Jackson 1978; Mori et al. 1981; Talora \& Morellato 2000; Bencke \& Morellato 2002) e em florestas estacionais semidecíduas (Morellato 1995; Morellato \& Leitão Filho 1990; 1992; 1996; Carmo \& Morellato 2000; Mirich \& Silva 2001). Na maioria destes estudos, os eventos fenológicos têm grande correlação com os índices de pluviosidade. Por outro lado, os estudos de Marques et al. (2004) e Marques \& Oliveira (2004), realizados no sul do Brasil,

\footnotetext{
Herbarium Anchieta do Instituto Anchietano de Pesquisas, UNISINOS, Rua Brasil 725, C. Postal 275, 93001-970 São Leopoldo, RS, Brasil

2 Universidade Federal do Rio Grande do Sul, Programa de Pós-Graduação em Botânica, Av. Bento Gonçalves 9500, 43433, 91105-970 Porto Alegre, RS, Brasil

3 Autor para correspondência: herbariopaca@unisinos.br
} 
têm demonstrado uma correlação maior entre os eventos fenológicos e os fatores de temperatura e comprimento do dia do que com a precipitação, devido à maior amplitude anual daquelas variáveis em regiões subtropicais.

As florestas de restinga, embora fortemente associadas com a floresta ombrófila densa, constituem um sistema fisionômico distinto, especialmente no sul do Brasil (Klein 1961). No Rio Grande do Sul, as florestas psamófilas constituem um dos clímaces da restinga, determinado principalmente pelas condições edáficas (Waechter 1985).

Existem dados dispersos sobre a fenologia de espécies arbóreas de restinga no Brasil meridional, como por exemplo Flora Ilustrada Catarinense (Reitz 1965), além de informações valiosas em herbários, dissertações e teses. No entanto, poucas são as informações disponíveis a cerca dos padrões fenológicos em nível de população, guilda, sinúsia ou comunidade. O presente trabalho objetivou registrar os padrões de florescimento e frutificação e aspectos do ciclo vegetativo das espécies arbóreas zoocóricas mais comuns em uma floresta psamófila do litoral sulrio-grandense, bem como avaliar possíveis relações entre os eventos fenológicos e as condições climáticas da região.

\section{Material e métodos}

Área de Estudo - A área de estudo localiza-se no município de Palmares do Sul, próxima à margem da Lagoa da Porteira, com ponto central próximo às coordenadas $30^{\circ} 21^{\prime} \mathrm{S}$ e $50^{\circ} 21^{\prime} \mathrm{W}$. O fragmento florestal estudado compreende uma área com cerca de 37 ha, com altitude média de seis metros s.n.m e distante cerca de sete quilômetros da linha da costa do oceano Atlântico.

O clima regional é do tipo $\mathrm{Cfa}$, segundo a classificação de Köppen, ou seja, subtropical úmido, sem período seco. Dados provenientes da estação meteorológica de Imbé, a cerca de $5 \mathrm{~km}$ do local de estudo, com altitude semelhante e mesma distância do oceano, indicaram (para o período de 1961 a 1990) temperatura média anual de $20^{\circ} \mathrm{C}$, sendo a média do mês mais quente superior a $24,5^{\circ} \mathrm{C}$ e a média do mês mais frio em torno de $15{ }^{\circ} \mathrm{C}$, com precipitação de $1.326 \mathrm{~mm}$ ano $^{-1}$.

Geomorfologicamente, a área de estudo compreende a unidade "Complexo Lagunar" (Justus et al. 1986), caracterizada por ser uma área plana, sem dissecações e com a presença de dunas e cordões lacustres, constantemente retrabalhados pela ação eólica. De acordo com Villwock \& Tomazelli (1998), os eventos de transgressão e regressão marinhos geraram um mosaico de depósitos sedimentares descontínuos, onde predominam as areias quartzosas. O solo da região é classificado como Neossolo quartzarênico, sendo profundo a medianamente profundo, com textura arenosa, encontrando-se bem drenado, além de apresentar baixa retenção de nutrientes e pouca fertilidade natural (Streck et al. 2000).

O remanescente florestal foi estudado quanto aos aspectos estruturais por Moraes \& Mondin (2001), indicando que a floresta possui porte relativamente baixo, com altura máxima de nove metros e dossel homogêneo. Devido à ação do vento, os indivíduos periféricos tocam o chão com suas copas, formando uma proteção para os que se dispõem logo atrás, deixando a borda com um aspecto de rampa. A borda da floresta nestes pontos é impenetrável. Embora ocorram sinais da presença de gado bovino, o estande está relativamente conservado, seja pela distribuição de diâmetros (Moraes \& Mondin 2001) ou pela abundância de epífitas, tais como líquenes, samambaias, peperômias, bromélias e orquídeas.

Procedimento Amostral - Para o acompanhamento fenológico foram selecionadas nove espécies bem representadas neste ambiente, de acordo com os dados estruturais apresentados por Moraes \& Mondin (2001), sendo todas, espécies zoocóricas (Tab. 1). O número de indivíduos de cada espécie variou de 10 a 16, acima dos valores mínimos propostos por Fournier \& Charpantier (1975). O material botânico coletado foi depositado no Herbário Anchieta (PACA), em São Leopoldo, RS. Foram selecionadas apenas espécies zoocóricas pelo fato desta guilda representar mais de $90 \%$ das espécies arbóreas amostradas em levantamento estrutural realizado na área (Moraes \& Mondin 2001). O foco nas espécies zoocóricas ocorreu também em função de subsidiar discussões sobre disponibilidade potencial de recursos diretos (frutos comestíveis) e indiretos (frutos atrativos à fauna) para as populações humanas pré-coloniais que habitaram esta região, em colaboração ao projeto "Formas PréColoniais de Estabelecimento e Economia no Litoral Central do Rio Grande do Sul", ao qual o presente trabalho esteve vinculado (Rogge 2005).

As observações foram realizadas mensalmente, entre maio/2002 a abril/2004. Os eventos fenológicos observados foram: queda foliar, brotamento, floração 
Tabela 1. Sincronia de atividade de cada fenofase, em porcentagem de indivíduos, estimado no período de maior atividade de cada espécie. $\mathrm{N}$ = número de indivíduos amostrados. $\mathrm{O}$ valor entre parênteses expressa o mês com maior atividade observada.

\begin{tabular}{lccccc}
\hline \multirow{2}{*}{ Espécie } & \multicolumn{3}{c}{ Fenofase } \\
\cline { 2 - 6 } & $\mathrm{N}$ & Queda de folhas & Brotação & Floração & Frutificação \\
\hline Casearia sylvestris Jacq. & 12 & 4 (jul-ago) & 50 (nov) & 83 (set) & 29 (set) \\
C. decandra Sw. & 15 & 63 (jul) & 36 (set) & 23 (fev) & 30 (mar) \\
Eugenia myrcianthes Nied. & 10 & 10 (jul) & 10 (nov) & 85 (out) & 45 (dez-jan) \\
E. uniflora L. & 12 & 25 (jul) & 70 (set) & 33 (set) & 33 (nov) \\
E. uruguayensis Camb. & 13 & - & 26 (nov) & 33 (jan) & 15 (set-out) \\
Lithraea brasiliensis March. & 13 & 7 (jul) & 50 (fev) & 38 (out) & 15 (nov) \\
Myrsine umbellata Mart. & 16 & - & 40 (ago) & 40 (jul) & 37 (nov) \\
Sideroxylum obtusifolium (Roem. \& Schult.) Penn. & 10 & 5 (jul) & 35 (set) & 90 (out) & 50 (nov) \\
Zanthoxylum fagara St-Hil. & 15 & 3 (jul) & 60 (set) & 63 (jun) & 20 (set-out) \\
\hline
\end{tabular}

e frutificação. O evento de queda foliar foi delimitado pela redução do número de folhas nas copas, constatadas como "falhas" e, confirmada pela presença das folhas sob a copa do indivíduo na serapilheira. O brotamento foi definido a partir do aparecimento de novos ramos e pequenas folhas brilhantes e, como fim da fenofase, quando a maioria das folhas atingia aproximadamente o tamanho e coloração das folhas adultas. Folhas novas foram registradas durante o período de brotamento, estendendo-se eventualmente além deste, até não haver mais diferenças entre as folhas recém produzidas e as demais.

Os dados climáticos utilizados no presente estudo foram fornecidos pelo Departamento Nacional de Meteorologia - DNMet, correspondendo ao período de estudo de maio/2002 a abril/2004. Através dos registros diários, foram obtidas médias mensais de temperaturas máxima, mínima e temperatura média, além dos valores de precipitação média mensal.

Análise dos dados - As fenofases foram avaliadas através do índice de atividade, o qual constata a presença-ausência do evento de modo individual, mas, em nível populacional, torna-se um método de caráter quantitativo, indicando a porcentagem de indivíduos da população que está manifestando a fenofase (Bencke $\&$ Morellato, 2002). Seguindo esta metodologia, o evento fenológico foi considerado: assincrônico $(<20 \%$ de indivíduos na fenofase); pouco sincrônico ou com baixa sincronia (20-60\% de indivíduos na fenofase); sincronia alta ( $>60 \%$ dos indivíduos na fenofase).

Para cada espécie, as proporções mensais de indivíduos em cada fenofase foram relacionadas às séries de dados de precipitação e temperatura e à média astronômica de comprimento do dia (Fig. 1), através de correlações por postos de Spearman (Zar 1996).
Embora temperatura média e comprimento do dia estejam estreitamente correlacionados $\left(r_{s}=0,82\right.$, $P<0,001)$, evidenciando elevada multicolinearidade entre ambas, as duas variáveis foram tratadas de forma separada para enfatizar pequenas variações, especialmente em relação à precipitação pluviométrica. Além da ausência de uma estação seca definida, a precipitação não apresentou correlação significativa com nenhuma das outras variáveis $\left(r_{s \text { temperatura } \times}\right.$ precipitação $=-0,31, P=0,3 ; r_{\text {s comprimento dia } \times \text { precipitaç̃o }}=-0,19$, $P=0,52)$.

Devido ao atraso que pode ser apresentado entre o estímulo ambiental e a resposta fenológica (Marques et al. 2004), verificaram-se as correlações entre os eventos fenológicos e as variáveis ambientais de um a três meses anteriores às observações (Marques et al. 2004) com os dados de 24 meses agrupados para um ano $(\mathrm{N}=12)$. Posteriormente, o conjunto de valores para todas as espécies foi relacionado às variáveis ambientais, sendo indicado como "guilda", já que não

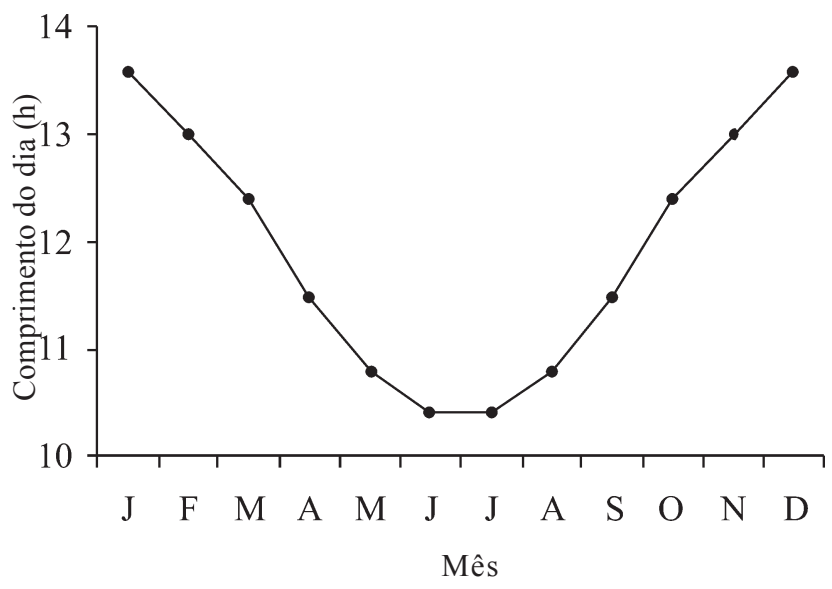

Figura 1. Média astronômica de comprimento do dia (hs) para a latitude sul de $30^{\circ}$, onde se encontra a área de estudo. 
abrigou todo o componente arbóreo, mas apenas parte da sinúsia.

\section{Resultados}

Queda foliar e brotamento - A queda de folhas foi uma fenofase de intensidade reduzida para a maioria das espécies, com os indivíduos apresentando baixa sincronia (Tab. 1), ocorrendo num ritmo estável durante a maior parte do ano. Houve um pequeno incremento durante o mês de julho (Fig. 2), quando ocorreu a menor média mensal de temperatura e o menor comprimento do dia. Os testes de correlação de Spearman indicaram que a guilda apresentou correlação negativa com temperatura e comprimento do dia, não apresentando relação com a precipitação (Tab. 2).

Das espécies analisadas, apenas Casearia decandra teve alta sincronia para queda de folhas, com quase todos os indivíduos perdendo-as no mês de julho. Os indivíduos da espécie Eugenia uniflora possuíram baixa sincronia para este evento, enquanto Casearia sylvestris e Eugenia myrcianthes foram assincrônicas, embora estas espécies tenham apresentado correlações significativas com as variáveis ambientais (Tab. 2). Myrsine umbellata e Eugenia uruguayensis possuem valores insignificantes para queda foliar, sendo típicas espécies perenifólias da floresta psamófila. Na maioria dos casos, as espécies correlacionaram-se com as variáveis de meses anteriores (médias de atraso variando de 0,4 a 1,7 meses).
O brotamento, ou seja, produção de folhas e ramos, para a maioria das espécies inicia-se no mês de agosto, prolongando-se até novembro, estando correlacionado com o aumento da temperatura média e o aumento do comprimento do dia (atraso médio de 1,7 a 2,6 meses). No entanto, quando se observam os valores da Tab. 2, verificam-se que as correlações são negativas na maioria das vezes. Este padrão ocorre pelo fato da maioria das espécies encerrarem a fase de brotamento até novembro, ou seja, antes de atingir o máximo de temperatura média anual e comprimento do dia, que ocorrem entre novembro e fevereiro, o que ocasiona um artefato no cálculo das correlações, não diminuindo a sua precisão, pois os valores são simétricos, positiva ou negativamente. Os testes de correlação de Spearman (Tab. 2) indicaram que a guilda apresentou correlação negativa com as variáveis ambientais de temperatura e comprimento do dia. Por outro lado, não houve correlação significativa entre brotamento e precipitação.

As espécies que apresentaram maior sincronia para brotamento foram Zanthoxylum fagara, Casearia sylvestris e Lithraea brasiliensis, sendo apenas Eugenia myrcianthes, assincrônica (Tab. 1). As demais espécies apresentaram graus intermediários de sincronia, correlacionando-se com comprimento do dia, temperatura e brevemente, com a precipitação. Esta última variável pode ser um fator associado, mas, não determinante à brotação, pois não existe período prolongado com bruscas alterações no regime de chuvas e mesmo períodos com déficit hídrico.

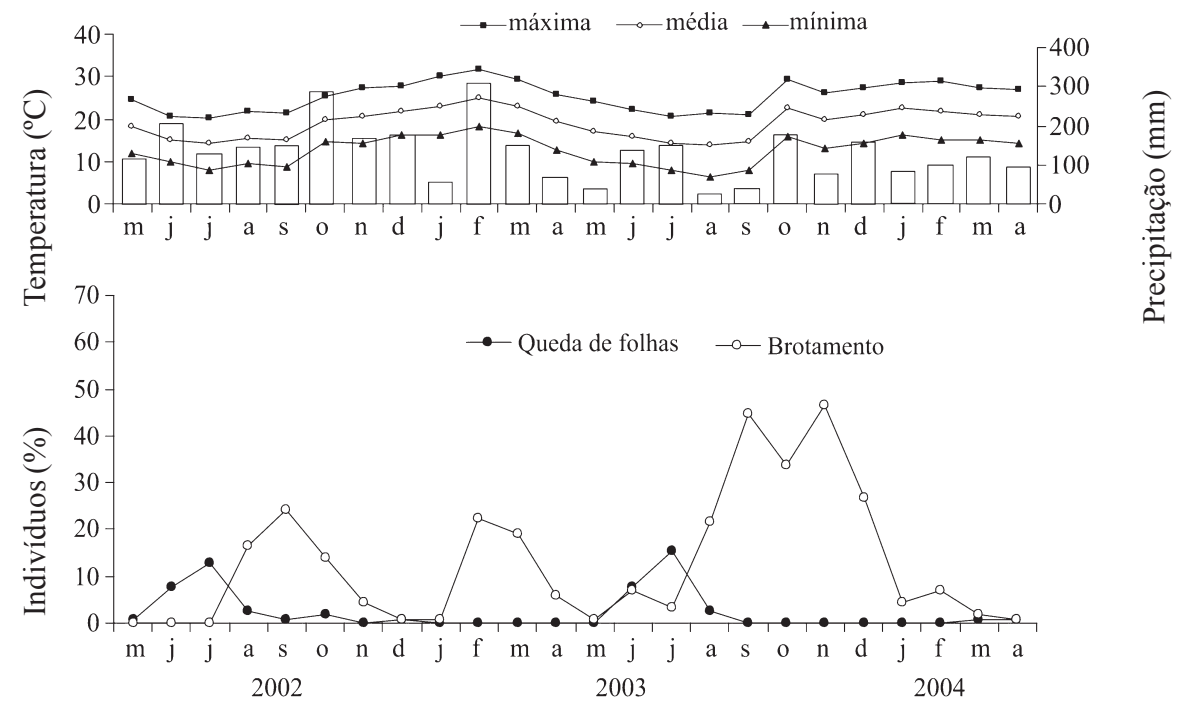

Figura 2. Queda de folhas e brotamento em espécies arbóreas zoocóricas de uma floresta psamófila no sul do Brasil. 
Tabela 2. Correlações de Spearman $\left(r_{s}\right)$ entre as fenofases e variáveis ambientais para as espécies e guilda de espécies arbóreas zoocóricas em uma floresta psamófila no sul do Brasil. $\mathrm{T}=$ temperatura média $\mathrm{em}{ }^{\circ} \mathrm{C} ; \mathrm{P}=$ precipitação pluviométrica em milímetros; $\mathrm{C}=$ comprimento do dia em horas. Entre parênteses, número de meses em que a fenofase apresentou a maior correlação com a variável ambiental em relação à data de observação. Meses de atraso representam a média \pm desvios padrão para as espécies, não considerando no cálculo, o valor relativo à guilda.

\begin{tabular}{|c|c|c|c|c|c|c|}
\hline \multirow[b]{2}{*}{ Espécie } & \multicolumn{3}{|c|}{ Fenofase $=$ queda de folhas } & \multicolumn{3}{|c|}{ Fenofase $=$ brotação } \\
\hline & $\mathrm{T}\left({ }^{\circ} \mathrm{C}\right)$ & $\mathrm{P}(\mathrm{mm})$ & $\mathrm{C}(\mathrm{h})$ & $\mathrm{T}\left({ }^{\circ} \mathrm{C}\right)$ & $\mathrm{P}(\mathrm{mm})$ & $\mathrm{C}(\mathrm{h})$ \\
\hline Casearia sylvestris & $-0,64^{*}(0)$ & $-0,51 \mathrm{~ns}(3)$ & $-0,62^{*}(2)$ & $-0,69^{* *}(3)$ & $0,37 \mathrm{~ns}(0)$ & $0,77^{* * *}(0)$ \\
\hline C. decandra & $-0,74^{* * *}(0)$ & $-0,29$ ns (3) & $-0,84^{* * *}(0)$ & $-0,67^{* *}(2)$ & 0,19 ns $(2)$ & $-0,69^{* *}(3)$ \\
\hline Eugenia myrcianthes & $-0,78^{* *}(1)$ & $0,48 \mathrm{~ns}(0)$ & $-0,78^{* *}(2)$ & $-0,61^{* *}(3)$ & $0,44 \mathrm{~ns}(1)$ & $0,71^{* *}(0)$ \\
\hline E. uniflora & $-0,69^{* *}(0)$ & $-0,53 \mathrm{~ns}(1)$ & $-0,76^{* *}(1)$ & $-0,30 \mathrm{~ns}(3)$ & $0,17 \mathrm{~ns}(1)$ & $-0,27 \mathrm{~ns}(3)$ \\
\hline E. uruguayensis & - & - & - & $-0,71^{* *}(3)$ & 0,44 ns (1) & $-0,47 \mathrm{~ns}(3)$ \\
\hline Lithraea brasiliensis & $-0,48 \mathrm{~ns}(0)$ & $-0,39 \mathrm{~ns}(2)$ & $-0,48 \mathrm{~ns}(1)$ & $-0,58^{*}(3)$ & $0,70^{*}(0)$ & $0,50 \mathrm{~ns}(0)$ \\
\hline Myrsine umbellata & - & - & - & $-0,80^{* *}(2)$ & 0,33 ns $(0)$ & $-0,72^{* *}(2)$ \\
\hline Sideroxylum obtusifolium & $-0,48 \mathrm{~ns}(0)$ & $-0,39$ ns (2) & $-0,48 \mathrm{~ns}(1)$ & $-0,54 \mathrm{~ns}(2)$ & $0,16 \mathrm{~ns}(3)$ & $-0,48 \mathrm{~ns}(3)$ \\
\hline Zanthoxylum fagara & $-0,47 \mathrm{~ns}(2)$ & 0,47 ns (1) & $0,50 \mathrm{~ns}(3)$ & $-0,87^{* * *}(3)$ & $0,21 \mathrm{~ns}(2)$ & $-0,82^{* * *}(3)$ \\
\hline Guilda & $-0,74^{* *}(0)$ & $-0,29 \mathrm{~ns}(2)$ & $-0,83^{* * *}(1)$ & $-0,72^{* *}(3)$ & $0,35 \mathrm{~ns}(0)$ & $-0,65^{*}(3)$ \\
\hline \multirow[t]{2}{*}{ Meses de atraso } & $0,4 \pm 0,7$ & $1,7 \pm 1,1$ & $1,4 \pm 0,9$ & $2,6 \pm 0,5$ & $1,1 \pm 1$ & $1,7 \pm 1,4$ \\
\hline & \multicolumn{3}{|c|}{ Fenofase $=$ floração } & \multicolumn{3}{|c|}{ Fenofase $=$ frutificação } \\
\hline Espécie & $\mathrm{T}\left({ }^{\circ} \mathrm{C}\right)$ & $\mathrm{P}(\mathrm{mm})$ & $\mathrm{C}(\mathrm{h})$ & $\mathrm{T}\left({ }^{\circ} \mathrm{C}\right)$ & $\mathrm{P}(\mathrm{mm})$ & $\mathrm{C}(\mathrm{h})$ \\
\hline Casearia sylvestris & $-0,81^{* * *}(1)$ & $0,14 \mathrm{~ns}(0)$ & $-0,79^{* * *}(2)$ & $-0,64^{*}(3)$ & $0,29 \mathrm{~ns}(1)$ & $-0,41 \mathrm{~ns}(3)$ \\
\hline C. decandra & $-0,19 \mathrm{~ns}(2)$ & $-0,60^{*}(1)$ & $-0,12 \mathrm{~ns}(3)$ & 0,56 ns (1) & $0,25 \mathrm{~ns}(0)$ & $0,54 \mathrm{~ns}(3)$ \\
\hline Eugenia myrcianthes & $-0,83^{* * *}(3)$ & 0,34 ns $(0)$ & $-0,67^{* *}(3)$ & $0,37 \mathrm{~ns}(0)$ & $-0,36 \mathrm{~ns}(0)$ & $0,61^{*}(0)$ \\
\hline E. uniflora & $-0,42 \mathrm{~ns}(2)$ & $0,53 \mathrm{~ns}(1)$ & $-0,37 \mathrm{~ns}(3)$ & $0,27 \mathrm{~ns}(1)$ & $0,26 \mathrm{~ns}(1)$ & $0,19 \mathrm{~ns}(2)$ \\
\hline E. uruguayensis & $0,57^{*}(1)$ & $0,56^{*}(1)$ & $0,73^{* *}(0)$ & $-0,81^{* * *}(1)$ & $-0,26 \mathrm{~ns}(2)$ & $0,75^{* *}(2)$ \\
\hline Lithraea brasiliensis & $-0,65^{*}(3)$ & $0,35 \mathrm{~ns}(0)$ & $-0,43$ ns (3) & $-0,76^{* * *}(1)$ & 0,27 ns (1) & $0,82^{* * *}(1)$ \\
\hline Myrsine umbellata & $-0,63^{*}(0)$ & $-0,46 \mathrm{~ns}(2)$ & $-0,66^{* *}(1)$ & $-0,64^{*}(2)$ & $0,18 \mathrm{~ns}(2)$ & $-0,58^{*}(3)$ \\
\hline Sideroxylum obtusifolium & $-0,73^{* *}(2)$ & $0,25 \mathrm{~ns}(0)$ & $-0,65^{*}(3)$ & $0,53 \mathrm{~ns}(1)$ & $0,17 \mathrm{~ns}(1)$ & $0,62^{*}(0)$ \\
\hline Zanthoxylum fagara & $0,83^{* * *}(3)$ & $-0,27 \mathrm{~ns}(2)$ & $-0,84^{* * *}(3)$ & $0,80^{* * *}(3)$ & $0,28 \mathrm{~ns}(2)$ & $-0,84^{* * *}(3)$ \\
\hline Guilda & $-0,52$ ns $(2)$ & $-0,44^{* *}(2)$ & $-0,48 \mathrm{~ns}(1)$ & $-0,61^{* *}(3)$ & $0,39 \mathrm{~ns}(3)$ & $0,82^{* * *}(3)$ \\
\hline Meses de atraso & $1,8 \pm 1$ & $0,7 \pm 0,8$ & $2,2 \pm 1,1$ & $1,4 \pm 1$ & $1,1 \pm 0,7$ & $1,8 \pm 1,2$ \\
\hline
\end{tabular}

${ }^{*} \mathrm{P}<0,05 ; * * \mathrm{P}<0,01 ; * * * \mathrm{P}<0,001 ;$ ns - não significativo

Das nove espécies analisadas, apenas uma pode ser considerada decídua (Casearia decandra), com pico na queda de folhas em julho. Todas as espécies apresentaram fase de brotamento, este ocorrendo de agosto a novembro, concomitante ao aumento do comprimento do dia e aumento da temperatura média.

Floração e frutificação - Todas as espécies floresceram durante o período de estudo, com ritmos que diferiram ao longo do ano, sendo que em setembro e outubro, houve um incremento de espécies em floração (Fig. 3). Sideroxylum obtusifolium apresentou o maior grau de sincronismo, com cerca de $90 \%$ dos indivíduos florescendo no mês de outubro, para os dois anos de observação. Além de S. obtusifolium, Eugenia myrcianthes, Casearia sylvestris e Zanthoxylum fagara foram as espécies que apresentaram indivíduos com alta sincronia na floração, sendo as demais, todas com média sincronia. As maiores correlações das espécies e variáveis ambientais foram entre Zanthoxylum fagara (atraso de três meses), Eugenia myrcianthes (atraso de três meses) e Casearia sylvestris (atraso de dois meses) com aumento da temperatura e aumento do comprimento do dia (Tab. 2). Casearia decandra e Eugenia uniflora não apresentaram correlação com nenhuma das variáveis ambientais analisadas, com indivíduos florescendo em diferentes períodos do ano. Para a guilda, os testes de correlação indicaram relação com precipitação e tendência de relação com comprimento do dia e temperatura. A fraca relação entre floração e estas duas últimas variáveis pode ser conseqüência da baixa sazonalidade deste evento, o qual ocorre ao longo do ano, variando de espécie para espécie. 

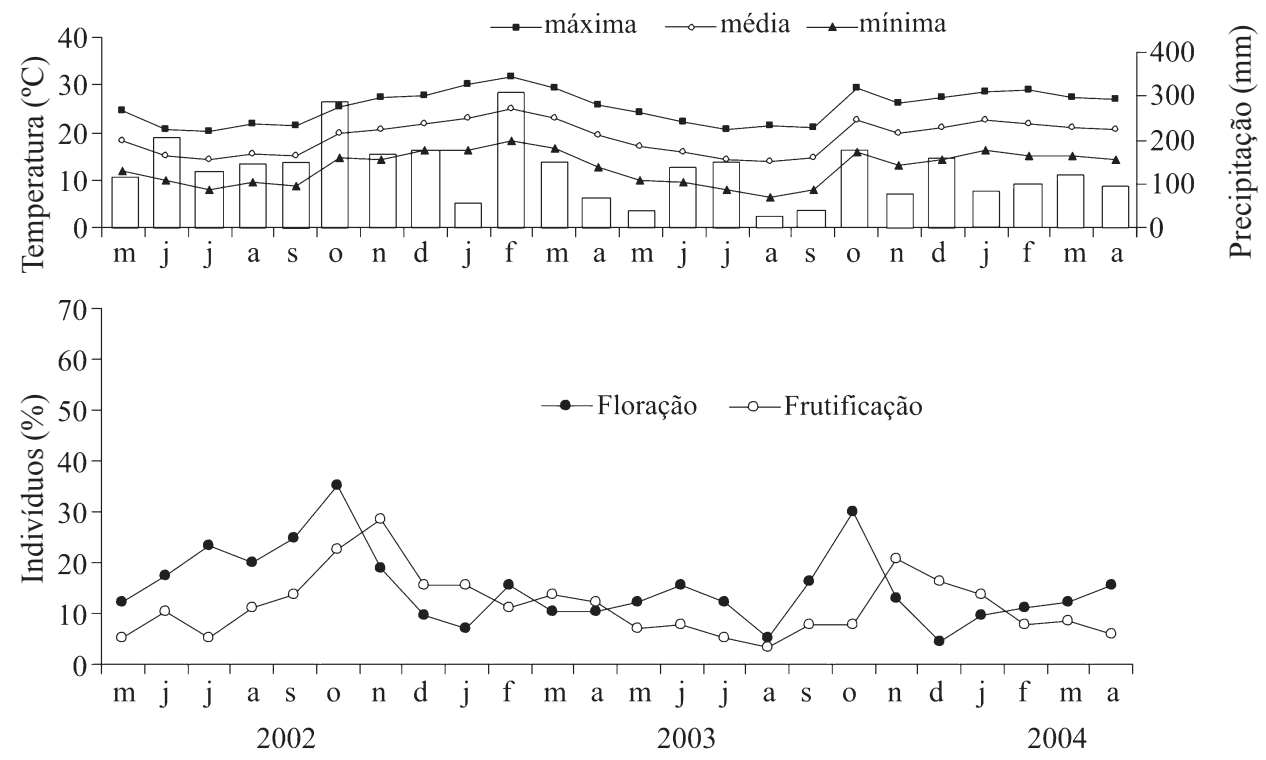

Figura 3. Floração e frutificação em espécies arbóreas zoocóricas de uma floresta psamófila no sul do Brasil.

A frutificação das espécies ocorreu durante todo o ano, com pico de atividades em novembro (Fig. 3), embora, com todas as espécies apresentando baixa sincronia ou mesmo assincronia para esta fenofase. Houve correlações significativas entre frutificação e aumento da temperatura e comprimento do dia. Por outro lado, nenhuma espécie apresentou relação entre frutificação e precipitação pluviométrica (Tab. 2). As maiores correlações foram de Zanthoxylum fagara (atraso médio de 3 meses) e Eugenia uruguayensis (atraso médio de 1,5 mês) com temperatura e comprimento do dia. Casearia decandra e Eugenia uniflora praticamente não apresentaram correlações significativas com as variáveis ambientais analisadas. No caso de Casearia sylvestris e Eugenia uniflora, a baixa sazonalidade da floração e inexpressiva sincronia desta fenofase, bem como a falta de correlação com as variáveis de ambiente resultaram na produção de frutos sem correlação com fatores ambientais. Quando analisadas as relações entre a guilda e as variáveis ambientais, observaram-se correlações positivas com temperatura e comprimento do dia e ausência de correlação com a precipitação pluviométrica (Tab. 2).

\section{Discussão}

Fenofases vegetativas e clima - O presente estudo revelou que a guilda de espécies arbóreas zoocóricas apresenta padrões fenológicos com uma periodicidade alta, estando correlacionados a duas variáveis ambientais: temperatura e comprimento do dia.

A fenofase com maior sazonalidade foi queda de folhas, evento quase restrito ao mês de julho, quando ocorre a menor temperatura média anual e a menor média de comprimento do dia. Marques et al. (2004) observaram padrões semelhantes para uma área de Floresta Ombrófila Mista, localizada em área de clima temperado, na região leste do estado do Paraná, sendo que este evento teve um pico nos meses de agostosetembro. Na floresta psamófila, o atraso médio foi de cerca de um mês, adiantando o processo de queda foliar em relação à floresta com Araucária. Contudo, nos dois casos, esta fenofase ocorre logo após ou durante os meses de menor temperatura média e menor comprimento do dia.

Em florestas tropicais estacionais, a queda de folhas tem sido freqüentemente associada com estações secas (Frankie et al. 1974; Bullock \& SolísMagallanes 1990), porém, em áreas sem estação seca definida, outros fatores tem sido designados como gatilhos ao desencadeamento de processos fisiológicos (Rivera \& Borchert 2001).

Ao analisarem diversas espécies oriundas de florestas tropicais estacionais da América e da Ásia, Rivera et al. (2002) encontraram um padrão definido de brotação durante o equinócio da primavera, coincidindo com o final da estação seca para muitas destas áreas. Entretanto, o final da estação seca apresentou grande variação inter anual, enquanto que o desencadeamento da brotação foi relativamente constante ao longo dos anos. As observações revelaram 
este padrão para o hemisfério norte e também, para o hemisfério sul, com um intervalo de seis meses entre ambos (Rivera et al. 2002), indicando que embora o padrão fenológico fosse constante, as variações climáticas existentes em cada área não indicariam uma única variável, como por exemplo, precipitação pluviométrica, como gatilho ao desencadeamento destes eventos. Por fim, os autores concluem que a variação sazonal do comprimento do dia está diretamente relacionada às fenofases vegetativas existentes naquelas áreas.

Embora o clima da região litorânea no Brasil meridional possua variações significativas de temperatura ao longo do ano, a quantidade de chuvas que chegam à área é bem distribuída por todos os meses, justificando a inexistência de correlação entre queda foliar e precipitação pluviométrica. Por outro lado, a variação de cerca de 3,5 horas no fotoperíodo ao longo do ano, associadas a alterações diretas na temperatura pode definitivamente desencadear respostas fisiológicas previsíveis em diversas espécies, tal qual observado no presente estudo e em outros realizados no sul do Brasil (Marques et al. 2004).

O brotamento das espécies atingiu maior intensidade após o período de queda de folhas, com menor sazonalidade, mas também correlacionados às variáveis ambientais. A produção de novas folhas é freqüentemente correlacionada com queda foliar, especialmente para espécies decíduas (Morellato et al. 1989), porém, a sincronia de brotamento a nível populacional, tem sido relacionada a uma estratégia de escape à herbivoria (Janzen 1975) ou para evitar a emissão de novas folhas durante estações desfavoráveis (van Schaik et al. 1993). Ainda segundo estes autores, a relação positiva entre brotação e maior comprimento do dia otimiza as taxas de produção fotossintética. A ausência de restrições hídricas na área, associada ao fato das espécies estudadas pertencerem a diferentes contingentes geográficos, onde a taxa de herbivoria e demais condicionantes biológicos possam ser distintos, parecem reduzir a pressão destes fatores como gatilhos às mudanças fenológicas vegetativas destas espécies.

Fenofases reprodutivas e clima - Ao contrário das fases vegetativas, as quais apresentaram acentuada sazonalidade, os eventos de floração foram menos sazonais, ocorrendo com um incremento durante os meses mais quentes e com dias mais longos, no entanto, com diferentes espécies florescendo ao longo de todo $\mathrm{o}$ ano. Um pequeno pico na produção de flores ocorreu em setembro-outubro, especialmente por espécies com indivíduos apresentando alta sincronia. Morellato et al. (1989) sugeriram que a floração poderia ser desencadeada pelo aumento do fotoperíodo, temperatura e umidade, em épocas de transição de estações. Por outro lado, Borchert (1983) afirmou que tais padrões deveriam considerar, num contexto expandido, fatores bióticos, edáficos e climáticos.

Embora a floração tenha apresentado fraca relação com variáveis ambientais, a frutificação apresentou correlação significativa com temperatura e fotoperíodo, com uma pequena elevação na produção de frutos entre outubro-novembro. Embora o pico de frutificação seja subseqüente ao pico de floração, a produção de frutos foi observada durante o ano todo, ocorrendo correlações menores entre este evento e as variáveis ambientais, tal qual observado por Marques et al. (2004) em uma área de Floresta Ombrófila Mista, a qual não apresenta períodos sistematicamente secos.

Segundo Morellato \& Leitão Filho (1992) a relação entre precipitação e frutificação é maior, sobretudo em áreas com florestas estacionais, onde o clima mais seco poderia favorecer espécies dispersas pelo vento. No levantamento estrutural realizado no mesmo fragmento de floresta psamófila (Moraes \& Mondin 2001) cerca de $90 \%$ das espécies foram zoocóricas, a maioria delas possuindo extensas áreas de distribuição (observação dos autores). Por outro lado, Budke et al. (2005) encontraram cerca de $70 \%$ de espécies zoocóricas e $20 \%$ de anemocóricas em uma floresta estacional situada na mesma latitude do presente estudo, corroborando a relação verificada por Morellato (dados não publicados) de que quanto maior a sazonalidade climática, especialmente precipitação pluviométrica, maior a porcentagem de espécies com frutos dispersos pelo vento e, ao nível comunitário, maior será a concentração de frutos em uma determinada faixa do ano.

Embora as florestas de restinga possuam ligação florística com as florestas pluviais tropicais sensu lato (Oliveira Filho \& Fontes 2000), as variações ambientais promovidas pelo aumento da latitude interferem diretamente nos padrões fenológicos apresentados pelas espécies, diferindo de outras florestas tropicais, pela ausência de período seco e, maior interferência da temperatura e fotoperíodo no desencadeamento dos eventos fenológicos.

\section{Agradecimentos}

Os autores agradecem ao Instituto Anchietano de Pesquisas/Unisinos, pela disponibilidade da infraestrutura bem como pelo financiamento do presente 
estudo. Nossos especiais agradecimentos ao Geógrafo Ricardo Braga, pelas valiosas informações sobre o clima do litoral sul-rio-grandense; às bolsistas Carine Foss, Gabriela Fausti-Landoni, Janine Barbosa e Luciane Baretta, pelo auxílio nos trabalhos de campo; ao Dr. Paulo Windisch, pela leitura crítica do manuscrito e sugestões; aos revisores anônimos, pelas correções e recomendações.

\section{Referências bibliográficas}

Alvin, P.T. \& Alvin, R. 1976. Relation of climate to growth periodicity in tropical trees. Pp. 455-464. In: P.B. Tomlinson \& M.H. Zimmerman (eds.). Tropical trees as living systems. Cambridge University Press.

Araújo, V.C. 1970. Fenologia de essências florestais amazônicas I. Boletim do INPA 4: 1-25.

Bencke, C.S.C. \& Morellato, L.P.C. 2002. Estudo comparativo da fenologia de nove espécies arbóreas em três tipos de floresta atlântica no sudeste do Brasil. Revista Brasileira de Botânica 25(2): 237-248.

Borchert, R. 1983. Phenology and control of flowering in tropical trees. Biotropica 15(2): 81-89.

Budke, J.C.; Athayde, E.A.; Giehl, E.L.H.; Záchia, R.A. \& Eisinger, S.M. 2004. Composição florística e espectro de dispersão de espécies lenhosas em uma floresta ribeirinha, arroio Passo das Tropas, Santa Maria, RS, Brasil. Iheringia, série Botânica 32(1): 17-24.

Bullock, S.H. \& Solís-Magallanes, J.A. 1990. Phenology of canopy trees of a tropical deciduous forest in Mexico. Biotropica 22(1): 22-35.

Carmo, M.R.B. \& Morellato, L.P.C. 2000. Fenologia de árvores e arbustos das matas ciliares da bacia do rio Tibagi, estado do Paraná, Brasil. Pp. 125-142. In: R.R. Rodrigues \& H.F. Leitão Filho (orgs.). Matas ciliares: conservação e recuperação. São Paulo, Edusp/Fapesp.

Fournier, L.A. \& Charpantier, C.O. 1975. El tamaño da amostra y la frecuencia de las observaciones en el estudio de las caracteristicas fenologicas de los árboles tropicales. Turrialba 25: 45-48.

Frankie, G.W.; Baker, H.G. \& Opler, P.A. 1974. Comparative phenological studies of trees in tropical lowland wet and dry forest sites of Costa Rica. Journal of Ecology 62: 881-913.

Jackson, J.F. 1978. Seasonality of flowering and leaf-fall in Brazilian subtropical lower montane moist forest. Biotropica 10: 38-42.

Janzen, D. 1975. Behavior of Himenaea courbaril when its pre-dispersal seed predator is absent. Science 189: 145-147.

Justus, J.O.; Machado, M.L.A. \& Franco, M.S.M. 1986. Geomorfologia. Pp. 313-404. In: Levantamento de Recursos Naturais 33. Rio de Janeiro, Instituto Brasileiro de Geografia e Estatística.
Ker, J.C.; Almeida, J. A.; Fasolo, P.J. \& Hochmüller, D. P. 1986. Pedologia. Pp. 405-540. In: Levantamento de Recursos Naturais 33. Rio de Janeiro, Instituto Brasileiro de Geografia e Estatística.

Klein, R.M. 1961. Aspectos fitofisionômicos da mata pluvial da costa atlântica do sul do Brasil. Boletín de la Sociedad Argentina de Botánica 9: 121-140.

Lieth, H. \& Schultz, G. 1976. Contributions from biometeorological workshops focusing on seasonality. Journal of Biogeography 3: 229.

Marques, M.C.M. \& Oliveira, P.E.A.M. 2004. Fenologia de espécies do dossel e do sub-bosque de duas florestas de restinga da Ilha do Mel, sul do Brasil. Revista Brasileira de Botânica 27(4): 713-723.

Marques, M.C.M.; Roper, J.J. \& Salvalaggio, A.P.B. 2004. Phenological patterns among plant life forms in a subtropical forest in Southern Brazil. Plant Ecology 173: 203-213.

Mirich, S.B. \& Silva, S.M. 2001. Composição florística e fenologia de espécies zoocóricas de remanescentes de floresta estacional semidecidual no centro-oeste do Paraná, Brasil. Acta Botanica Brasilica 15(1): 89-113.

Moraes, D. \& Mondin, C.A. 2001. Florística e fitossociologia do estrato arbóreo em mata arenosa no Balneário do Quintão, Palmares do Sul, Rio Grande do Sul. Pesquisas, série Botânica 51: 87-100.

Morellato, L.P.C.; Rodrigues, R.R.; Leitão Filho, H.F. \& Joly, C.A. 1989. Estudo fenológico comparativo de espécies arbóreas de floresta de altitude e floresta mesófila na Serra do Japi, Jundiaí, SP. Revista Brasileira de Botânica 12: 85-98.

Morellato, L.P.C. \& Leitão Filho, H.F. 1990. Estratégias fenológicas de espécies arbóreas em floresta mesófila na Serra do Japi, Jundiaí, SP. Revista Brasileira de Biologia 50: 163-173.

Morellato, L.P.C. \& Leitão Filho, H.F. 1992. Padrões de frutificação e dispersão na Serra do Japi. Pp. 112-140. In: L.P.C. Morellato (org.). História natural da Serra do Japi: ecologia e preservação de uma área florestal no Sudeste do Brasil. Campinas, Unicamp.

Morellato, L.P.C. \& Leitão Filho, H.F. 1996. Reproductive phenology of climbers in a South-eastern Brazilian forest. Biotropica 28: 180-191.

Morellato, L.P.C. 1995. As estações do ano na floresta. Pp. 37-41. In: L.P.C. Morellato \& H.F. Leitão Filho (orgs.). Ecologia e preservação de uma floresta tropical urbana. Campinas, Unicamp.

Moreno, J.A. 1961. Clima do Rio Grande do Sul. Porto Alegre, Secretaria da Agricultura - Div. Terras e Colonização.

Mori, S.A.; Bloom B.M. \& Prance, G.T. 1981. Distributional patterns and conservation of Eastern Brazilian coastal forest tree species. Brittonia 33: 233-245.

Oliveira Filho, A.T. \& Fontes, M.A.L. 2000. Patterns of floristic differentiation among Atlantic forests in Southeastern Brazil and the influence of climate. Biotropica 32: 793-810.

Reitz, R. 1965. Plano de coleção. Flora Ilustrada Catarinense 1: 3-71. 
Rivera, G. \& Borchert, R. 2001. Induction of flowering in tropical trees by a 30 -min reduction in photoperiod: evidence from field observations and herbarium specimens. Tree Physiology 21: 201-212.

Rivera, G.; Elliott, S.; Caldas, L.S.; Nicolossi, G.; Coradin, V.T.R. \& Borchert, R. 2002. Increasing day-lenght induces spring flushing of tropical dry forest trees in the absence of rain. Trees 16: 445-456.

Rogge, J.H. 2005. Fenômenos de fronteira: um estudo das situações de contato entre os portadores das tradições cerâmicas pré-históricas no Rio Grande do Sul. Pesquisas-Antropologia 62: 1-125.

Schaik, C.P. van; Terborgh, J.W. \& Wright, S.J. 1993. The phenology of tropical forests: adaptative significance and consequences for primary consumers. Annual Review of Ecology and Systematics 24: 353-377.
Streck, E.V.; Kämpf, N.; Dalmolin, R.S.D.; Klamt, E.; Nascimento, P.C. \& Schneider, P. 2002. Solos do Rio Grande do Sul. Porto Alegre, EMATER/UFRGS.

Talora, D.C. \& Morellato, L.P.C. 2000. Fenologia de espécies arbóreas em floresta de planície litorânea do sudeste do Brasil. Revista Brasileira de Botânica 23(1): 13-26.

Villwock, J.A. \& Tomazelli, L.J. 1998. Holocene coastal evolution in Rio Grande do Sul, Brazil. Quaternary of South America and Antarctic Peninsula 11: 283-296.

Waechter, J.L. 1985. Aspectos ecológicos da vegetação de restinga no Rio Grande do Sul, Brasil. Comunicações do Museu de Ciências da PUC-RS, Série Botânica 33: 49-68.

Zar, J.H. 1996. Bioestatistical analysis. Prentice-Hall, New Jersey. 